The Journal of Engineering and Exact Sciences - jCEC, Vol. 06 N. 02 (2020)

journal homepage: https://periodicos.ufv.br/ojs/jcec

doi: 10.18540/jcecvl6iss2pp0193-0199

OPEN ACCESS - ISSN: 2527-1075

\title{
POSFUST RELIABILITY OF A NON-REPAIRABLE MULTI-STATE SYSTEM WITH POSFUST FAILURE RATE ESTIMATION
}

Harendra YADAV ${ }^{1}$, M. K. SHARMA², Vishnu Narayan MISHRA ${ }^{3}$

${ }^{1}$ Department of Mathematics, C.C.S. University, Meerut, Uttar Pradesh 250004, India, ORCID: https://orcid.org/0000-0002-7083-7434, talktoharendrayadav@gmail.com

${ }^{2}$ Department of Mathematics, C.C.S. University, Meerut, Uttar Pradesh 250004, India, ORCID: https://orcid.org/0000-0003-3071-5931,drmukeshsharma@gmail.com

${ }^{3}$ Department of Mathematics, Indira Gandhi National Tribal University, Lalpur, Amarkantak, Anuppur, Madhya Pradesh 484 887, India, ORCID: http://orcid.org/0000-0002-2159-7710, vishnunarayanmishra@gmail.com

\section{A R T I C L E IN F O}

Article history:

Received 2020-04-10

Accepted 2020-06-17

Available online 2020-06-17

keywords

Fuzzy set

Possibility

Non-repairable multi-state system

(NRMSS)

Markov process,

Posfust measure

Necfust measure

Failure rate
A B S T R A C T

Present research paper attempts to estimate the posfust reliability of a non-repairable multistate system (NRMSS). Failure rate estimation is key factor in the reliability estimation. But due to uncertainty in the environment and probabilistic measure, the absolute measurement of the failure rate is quite tedious. In this research paper, we have introduced a new measure for failure rate estimation using possibilistic measure based on fuzzy logic. In this work for the effective measurements of reliability, we have tried to cover the uncertainty in the failure rate at every state failure level. In this research paper, we have taken a non-repairable three state system and failure rate transition of every state is taken in the form of upper and lower bound in possibilistic measure. In this approach, Markov process (multi-state system) is used for getting the governing differential equation for transition from one state to another state. Numerical computations are also being carried out to estimate the posfust reliability. 


\section{INTRODUCTION}

The reliability of a system or a component is defined as its assigned functioning properly for a predicted period under given operating conditions; the classical reliability means the probability of non-failure of a system over time. Reliability basically depends upon two basic assumptions: the system's behaviour and its dichotomous state. In real situations, the concept of a dichotomous state is not sufficient to explain the system states. It may be seen that in intermediate situation systems behaviour and its partially working state at any instant cannot be explained with a different probability measure.

Such types of systems are called multi-state system (MSS) due to variation in its performance level. It may be also observed that complex systems are more reliable due to its multi-state structure. The reliability of various complex systems is calculated with the help of such multi-state models and claimed that the performance of multi-state systems are better than two state systems. Multi state system was observed by Lisnianski and Levitin (2003). The dichotomous state of the systems was replaced by the fuzzy states due to the logic given by L.A. Zadeh (1965).

Data collection is very crucial in very fast varying realworld problems. The collected data or the parameter may be imprecise and may have incomplete information. To deal with such situations, fuzzy logic is a marvellous tool. Possibility theory provides better result in the reliability evaluation of multi-state systems.

Models for multi-state system when transition and performance rates are fuzzy for fuzzy reliability assessment were observed by Liu and Huang (2010). Reliability of a fuzzy multi-state system having an exponential failure rate by constructing the Bayesian point estimation reported by Bamrungsetthapong and Pongpullponsak in (2015 \& 2017). They also observed the reliability of a non-repairable fuzzy multi-state series-parallel system using a hybrid technique between point estimation and interval estimation.

To overcome this randomness and getting a realistic result, probabilistic measure may be replaced by possibilistic measure. But in fuzzy reliability, the systems behaviour is fully characterized by the random uncertainty i.e. probability. The concept of fuzzy reliability was introduced by Cai and Wen (1991) and gave the formulation for the fuzzy reliability. Zadeh in 1965 gave the concept of fuzzy logic. He proposed grading function in place of characteristic function. Grading function plays a vital role in multi-state system. Concept of possibility was given by Zadeh (1978) in the context of fuzzy sets possibility theory which deals with the evidences. To cover up the uncertainties due to incomplete information and imprecise data, possibility involve two types of measures.
Decision making under possibility uncertainty have been proposed by Inuiguchi et.al. (2003). Properties of fuzzy rule-based reasoning with certainty qualification, using necessity measure was observed by Inuiguchiand Kume (1992). In the context of decision making under uncertainty, Dubois and Prade (1991) showed a kind of possibility and necessity measures used as a utility function by giving a set of axioms on the preference relation between possibility distributions. Pandey and Tyagi (2007) described the profust reliability of a gracefully degraded system using the fuzzy state and probability assumption. Chen et.al. (2017) proposed a new characterization of possibility measures, and necessity measures and coincidence of universal integrals for possibility measures and necessity measures".

This research work is distributed in to six sections. Section 2 deals with the basic definitions and proposed definitions, which will be used in the proposed algorithm and also describes for posfust estimation of a system. The structure of a non-repairable multi-state system with major and minor failures is presented in section 3. Section 4 of the research paper presents the algorithm of the proposed approach while in section 5 of the research paper mathematical expressions have been carried out for posfust reliability estimation and numerical computations have also been done. In the last section of the research paper, result discussion and conclusion are also being done.

\section{BASIC DEFINITIONS}

\subsection{Fuzzy set}

Membership function represents the belongingness of each element of a universal set $X$ to the unit interval $[0,1]$. A fuzzy set is denoted by the pair shown below by equation (1) as:

$$
\tilde{A}=\left\{x, \mu_{\tilde{A}}(x): x \in X\right\}
$$

and $\mu_{\tilde{A}}(x): X \rightarrow[0,1]$ is the membership function.

\subsection{Possibility theory}

Possibility theory deals with the bodies of evidence and whose focal elements are nested. Possibility theory depends upon two measures, i.e. one measure is possibility measure and the other is necessity measure. When fuzzy logic comes into the contact of these two measures, this converts into the posfust measure and necfust measure.

\subsection{Necfust measure}

Let $X$ be a universal set and $\tilde{A}_{k} \in P(X)$ be a fuzzy set of a non-empty family of subsets of $X$, then a fuzzy measure on $\langle X, P(X)\rangle$ is called a necfust measure $(N f)$ if: 


$$
N f\left(\bigcap_{k \in K} \mu_{\tilde{A}_{k}}(x)\right)=\min _{k \in K} N f\left(\mu_{\tilde{A}_{k}}(x)\right) \ldots \ldots \ldots(2)
$$

For all $\left\{\tilde{A}_{k}: k \in K\right\}$ in $P(X)$, such that $\tilde{A}_{k} \in P(X)$, where $K$ is an arbitrary index set.

\subsection{Posfust measure}

Let $X$ be a universal set and $\tilde{A}_{k} \in P(X)$ be a fuzzy set of a non-empty family of subsets of $X$, then a fuzzy measure on $\langle X, P(X)\rangle$ is called a posfust measure $(P f)$ if:

$$
\operatorname{Pf}\left(\bigcup_{k \in K} \mu_{\tilde{A}_{k}}(x)\right)=\max _{k \in K} \operatorname{Pf}\left(\mu_{\tilde{A}_{k}}(x)\right) \ldots . .(3)
$$

For all $\left\{\tilde{A}_{k}: k \in K\right\}$ in $P(X)$, such that $\tilde{A}_{k} \in P(X)$, where $K$ is an arbitrary index set.

\section{NON-REPAIRABLE FUZZY MULTI-STATE SYSTEM}

Markovian model is mostly used to estimate the possible number of failures of a system during any time interval. A markov process is a stochastic process, which depends on the present state position for transition from one state to another state, not on the previous state.

Let $l$ is the initial state and system is working with its full performance in this state. After degradation, system reaches in the state $m$ with less performance.

Due to the minor failure, the system transits from best state $l$ to $(l-1, \ldots m, \ldots 2,1)$ fail state. The transition of the system from state $l$ to $m$ is denoted by $\lambda_{l, m}$ and $(m<l-1)$, where $\lambda$ is the failure rate of the system transition from one state to another state. The diagram of a non-repairable multi-state system bearing major failure as well as minor failure is presented in Figure 1. The related differential equations for the above Markov model are:

$$
\begin{aligned}
& \frac{d P_{n}(t)}{d t}=-P_{n}(t) \sum_{m=1}^{n-1} \lambda_{l, m} \ldots \ldots \ldots . .(4) \\
& \frac{d P_{l}(t)}{d t}=\sum_{m=l+1}^{n} \lambda_{m, l} P_{m}(t)-P_{l}(t) \sum_{m=1}^{l-1} \lambda_{l, m} \ldots . .(5), \\
& l=2,3 \ldots \ldots . n-1 \\
& \frac{d P_{1}(t)}{d t}=\sum_{m=2}^{n} \lambda_{m, 1} P_{m}(t) \ldots \ldots .(6)
\end{aligned}
$$

Here, $P_{n}(t)$ denotes the probability that $\mathrm{n}$ components are contributing in system functioning at time $t$. Therefore, the

$$
\begin{aligned}
& \text { initial conditions } \quad \text { are as } \quad P_{n}(0)=1 \quad \text { and } \\
& P_{n-1}(0)=P_{n-2}(0)=\ldots . .=P_{1}(0)=0 .
\end{aligned}
$$

The solution of the above differential equations using initial conditions can be obtained also for large $n$. The sum of the probabilities of unacceptable states is the unreliability function for the multistate system. Then reliability function of a multistate system has the form shown below by equation (7):

$$
R_{\text {NRMSS }}(t)=1-\sum_{m=1}^{l} P_{m}(t) \ldots \ldots .(7)
$$

We are considering a three-state system for reliability evaluation with some minor failure. In state 3 systems is working with full efficiency while in state 2 with a less efficiency and completely failed in state 1 .

We have taken the three-state system with failure rates for transition 3 to $2=0.25 \&$ for 2 to $1=0.35$. First, we fuzzify these failure rates and present these with the corresponding trapezoidal fuzzy numbers. As the failure rates are fuzzy, so the fuzzy state possibility $\operatorname{Pos}_{1}(t)$ at time $t$ will be posfust also. When system reaches from state three to partially working state two, fuzzy failure rate is denoted by $\lambda_{3,2}$ and from state two to fail state (state 1), fuzzy failure rate is denoted by $\lambda_{2,1}$ (Figure 2).

So, the Fuzzy state possibility differential equations in this case may be obtained as follows by equations (8), (9) and (10):

$$
\begin{aligned}
& \frac{d \operatorname{Pos}_{3}(t)}{d t}=-\lambda_{3,2} P_{3}(t) \ldots \ldots(8) \\
& \frac{d \operatorname{Pos}_{2}(t)}{d t}=\lambda_{3,2} P_{3}(t)-\lambda_{2,1} P_{2}(t) \ldots \\
& \frac{d \operatorname{Pos}_{1}(t)}{d t}=\lambda_{2,1} P_{2}(t) \ldots \ldots(10)
\end{aligned}
$$

On solving the linear differential equation system, we get the fuzzy sate possibilities as follows by equations (11), (12) and (13):

$$
\begin{aligned}
& \operatorname{Pos}_{3}(t)=e^{-\lambda_{3,2} t} \ldots \ldots . .(11) \\
& \operatorname{Pos}_{2}(t)=\frac{\lambda_{3,2}}{\lambda_{3,2}-\lambda_{2,1}}\left(e^{-\lambda_{2,1} t}-e^{-\lambda_{3,2} t}\right) \ldots . .(12) \\
& \operatorname{Pos}_{1}(t)=1+\frac{1}{\lambda_{3,2}-\lambda_{2,1}}\left(\lambda_{3,2} e^{-\lambda_{2,1} t}-\lambda_{2,1} e^{-\lambda_{3,2} t}\right) \ldots .
\end{aligned}
$$

And the reliability function is given by equation (14) as:

$R_{\text {NRMSS }}(t)=1-\sum_{m=1}^{l} \operatorname{Pos}_{m}(t) \ldots . .(14)$ 


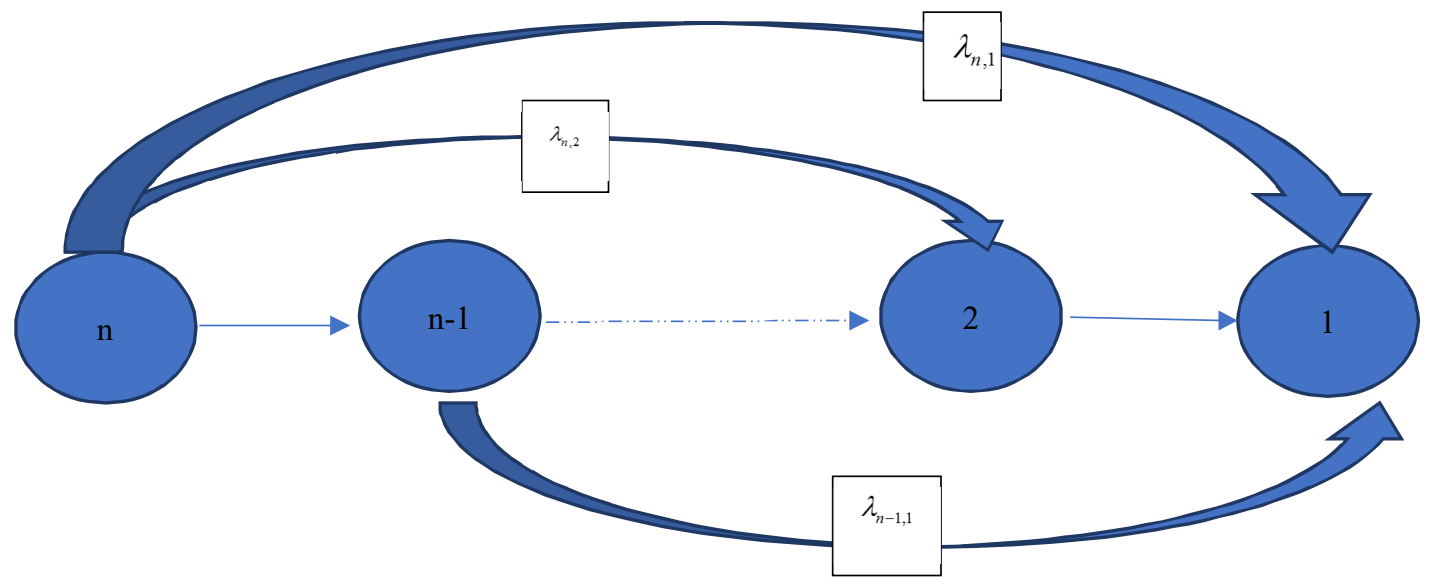

Figure 1. A non-repairable multi state system having $\mathrm{n}$ states due to minor and major failures

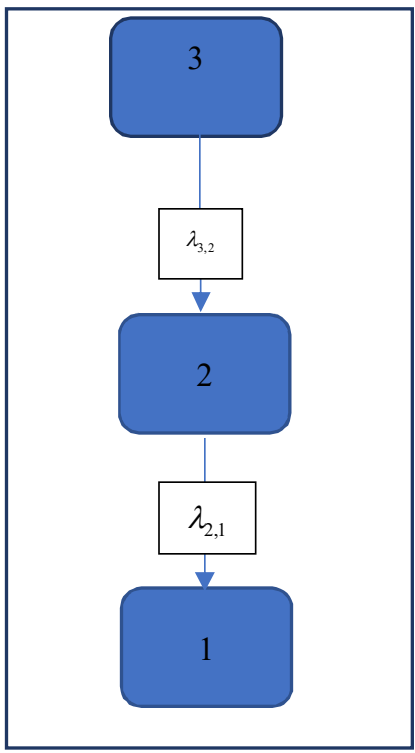

Figure 2. System having three stages from best state to fail state

\section{ALGORITHM FOR THE PROPOSED WORK}

In this research paper, we try to give the novel concept for failure rate estimation based on fuzzy logic and possibilistic measure. Reliability of non-repairable multistate system has been analysed by using the possibilistic failure rate estimation known as posfust reliability. In this section, we propose an algorithm for proposed failure rate and reliability estimation. Proposed algorithm is as follows:

1. First, we will construct trapezoidal fuzzy number for the failure rate as per the data provided by the expert's decision or on the bases of performance of the system.

2. Then select the focal elements of the fuzzy numbers using $\alpha$ - cut method obtained in step 1 and calculate their membership grade.

3. From the membership grade as obtained in step 2, we evaluate the posfust and necfust measure.

4. From the values of posfust and necfust measure as obtained in step 3, we find the maximum value of posfust measure and minimum value of necfust measures to cover up the wider range of uncertainty in the failure rate estimation.

5. To construct the single value of the membership, we take average of the maximum value of posfust measure and minimum of necfust measure as obtained in step 4and try to get the possible value of possibilistic failure rate, known as fuzzy failure rate.

a. Possible membership

b. $=($ Max of posfust measure + Min of necfust measure) / 2

c. $=$ Fuzzy failure rate

6. Using the values of fuzzy failure rate as obtained in step 5, possibilistic reliability is evaluated for every state.

7. In this last step of the algorithm, posfust reliability of the proposed system is evaluated, which works as the markovian approach for non-repairable multi-state system. 


\section{NUMERICAL COMPUTATIONS}

\subsection{For transition state 3 to 2}

In this case, the system failure rate $(0.25)$ for transition from state 3 to 2 is considered and this failure rate is represented by a trapezoidal fuzzy number as shown in Figure 3 .

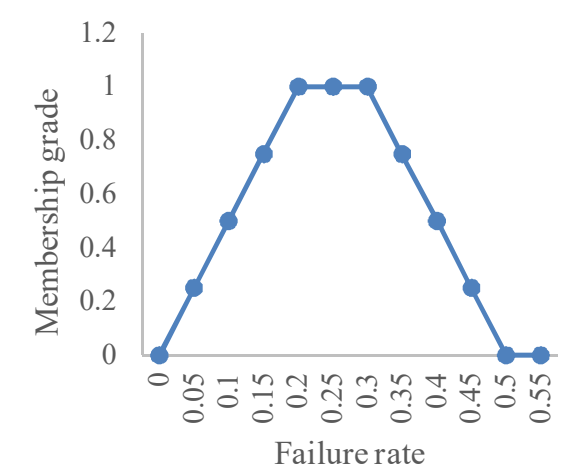

Figure 3. Trapezoidal fuzzy number for failure rate for state 3 to 2 .

Here $\quad \tilde{A}_{1}, \tilde{A}_{2}, \tilde{A}_{3} \quad$ and $\quad \tilde{A}_{4} \in \tilde{A} \quad$,where $\tilde{A}=\left\{a_{1}, a_{2} \ldots \ldots . a_{11}\right\}$, where $a_{1}, a_{2} \ldots \ldots . a_{11}$ are the grades corresponding to failure rate values 0 , $0.05 \ldots . .0 .45,0.5$ respectively.

Focal elements for $\alpha$-cuts are $\tilde{A}_{1}=\left\{a_{5}, a_{6}, a_{7}\right\}$

$$
\begin{aligned}
& \tilde{A}_{2}=\left\{a_{4}, a_{5}, a_{6}, a_{7}, a_{8}\right\} \\
& \tilde{A}_{3}=\left\{a_{3}, a_{4}, a_{5}, a_{6}, a_{7}, a_{8}, a_{9}\right\} \\
& \tilde{A}_{4}=\left\{a_{2}, a_{3}, a_{4}, a_{5}, a_{6}, a_{7}, a_{8}, a_{9}, a_{10}\right\}
\end{aligned}
$$

Then membership function for the above figure is followed by equation (15) as:

$$
\mu_{A}(x)= \begin{cases}\frac{x-a_{1}}{a_{5}-a_{1}} & 0 \leq x \leq 0.2 \\ 1 & 0.2 \leq x \leq 0.3 \\ \frac{a_{11}-x}{a_{11}-a_{7}} & 0.3 \leq x \leq 0.5 \\ 0 & x \leq 0, \quad x \geq 0.5\end{cases}
$$

And

$a_{1}=0, a_{2}=\frac{1}{4}, a_{3}=\frac{1}{2}, a_{4}=\frac{3}{4}, a_{5}=1, a_{6}=1, a_{7}=1, a_{8}=\frac{3}{4}, a_{9}=\frac{1}{2}, a_{10}=\frac{1}{4}, a_{11}=0$ are the membership grades corresponding to failure rate values. Now the posfust measure (by using equation (3)) is evaluated as follows;

$$
\begin{aligned}
& \operatorname{Pf}\left(\tilde{A}_{1}\right)=M \operatorname{ax}\left\{a_{5}, a_{6}, a_{7}\right\}=1 \\
& \operatorname{Pf}\left(\tilde{A}_{2}\right)=M \operatorname{ax}\left\{a_{4}, a_{5}, a_{6}, a_{7}, a_{8}\right\}=1 \\
& \operatorname{Pf}\left(\tilde{A}_{3}\right)=M \operatorname{ax}\left\{a_{3}, a_{4}, a_{5}, a_{6}, a_{7}, a_{8}, a_{9}\right\}=1 \\
& \operatorname{Pf}\left(\tilde{A}_{4}\right)=M \operatorname{ax}\left\{a_{2}, a_{3}, a_{4}, a_{5}, a_{6}, a_{7}, a_{8}, a_{9}, a_{10}\right\}=1
\end{aligned}
$$

And now $B_{1}, B_{2}, B_{3}$ and $B_{4}$ are the compliments of $\tilde{A}_{1}, \tilde{A}_{2}, \tilde{A}_{3}$ and $\tilde{A}_{4}$ respectively.

$$
\begin{aligned}
& \operatorname{Pf}\left(B_{1}\right)=M \operatorname{ax}\left\{a_{1}, a_{2}, a_{3}, a_{4}, a_{8}, a_{9}, a_{10}, a_{11}\right\}=\frac{3}{4} \\
& \operatorname{Pf}\left(B_{2}\right)=M \operatorname{ax}\left\{a_{1}, a_{2}, a_{3}, a_{9}, a_{10}, a_{11}\right\}=\frac{1}{2} \\
& \operatorname{Pf}\left(B_{3}\right)=M \operatorname{ax}\left\{a_{1}, a_{2}, a_{10}, a_{11}\right\}=\frac{1}{4} \\
& \operatorname{Pf}\left(B_{4}\right)=M \operatorname{ax}\left\{a_{1}, a_{11}\right\}=0
\end{aligned}
$$

Further, evaluation of necfust measure using the relation:

$N f\left(\tilde{A}_{i}\right)=1-N f\left(\tilde{B}_{i}\right)$; for all $i=1,2,3,4$.

$N f\left(\tilde{A}_{1}\right)=\frac{1}{4} \quad, \quad N f\left(\tilde{A}_{2}\right)=\frac{1}{2} \quad, \quad N f\left(\tilde{A}_{3}\right)=\frac{3}{4}$,

$N f\left(\tilde{A}_{4}\right)=1$

Now

$\operatorname{Max}\left\{\operatorname{Pf}\left(\tilde{A}_{1}\right), \operatorname{Pf}\left(\tilde{A}_{2}\right), \operatorname{Pf}\left(\tilde{A}_{3}\right), \operatorname{Pf}\left(\tilde{A}_{4}\right)\right\}=1$

and $\operatorname{Min}\left\{N f\left(\tilde{A}_{1}\right), N f\left(\tilde{A}_{2}\right), N f\left(\tilde{A}_{3}\right), N f\left(\tilde{A}_{4}\right)\right\}=\frac{1}{4}$

Average $=(1+1 / 4) / 2=0.625$ (possible membership grade)

Corresponding to membership grade $(0.625)$, we get an interval of failure rate values $[0.125,0.375]$, which is the range of expected failure chance.

\subsection{For transition state2 to 1}

Failure rate transition from state 2 to 1 or $\lambda_{2,1}$ is 0.35 and this failure rate is represented by a trapezoidal fuzzy number as shown in Figure 4.

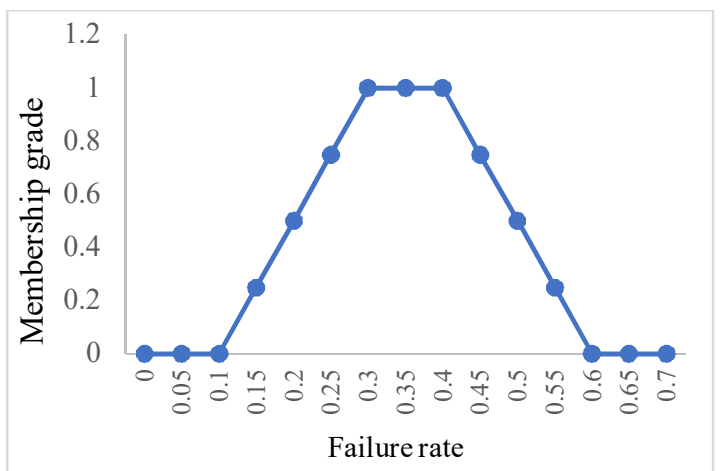

Figure 4. Trapezoidal fuzzy number for failure rate for state 2 to 1. 
Following the similar process, for transition from state 2 to 1 , the membership grade observed and corresponding to this grade, again we get interval valued failure rate $[0.225$, 0.475]. Further, numerical computations are given in the Table 1 and Table 2.

Table1. Showing the results for reliability with crisp failure rate

\begin{tabular}{|c|c|}
\hline $\begin{array}{c}\text { Time } \\
\text { (hours) }\end{array}$ & Reliability \\
\hline 0 & 1 \\
\hline 1 & 0.7780 \\
\hline 2 & 0.6067 \\
\hline 3 & 0.4721 \\
\hline 4 & 0.3677 \\
\hline 5 & 0.2857 \\
\hline 6 & 0.2230 \\
\hline 7 & 0.1728 \\
\hline 8 & 0.1352 \\
\hline 9 & 0.1046 \\
\hline 10 & 0.0820 \\
\hline 11 & 0.0638 \\
\hline 12 & 0.0485 \\
\hline 13 & 0.0381 \\
\hline 14 & 0.0296 \\
\hline 15 & 0.0235 \\
\hline
\end{tabular}

Table 2. Showing the results for posfust reliability with fuzzy failure rate

\begin{tabular}{|c|c|c|}
\hline $\begin{array}{c}\text { Time } \\
\text { (hours) }\end{array}$ & $\begin{array}{c}\text { Lower } \\
\text { Reliability } \\
\text { Range }\end{array}$ & $\begin{array}{c}\text { Upper } \\
\text { Reliability } \\
\text { Range }\end{array}$ \\
\hline 0 & 1 & 1 \\
\hline 1 & 0.6883 & 0.8821 \\
\hline 2 & 0.4722 & 0.7785 \\
\hline 3 & 0.3248 & 0.6869 \\
\hline 4 & 0.2216 & 0.6066 \\
\hline 5 & 0.1543 & 0.5359 \\
\hline 6 & 0.1057 & 0.4716 \\
\hline 7 & 0.0726 & 0.4160 \\
\hline 8 & 0.0415 & 0.3672 \\
\hline 9 & 0.0346 & 0.3242 \\
\hline 10 & 0.0239 & 0.2858 \\
\hline 11 & 0.0162 & 0.2519 \\
\hline 12 & 0.0104 & 0.2221 \\
\hline 13 & 0.0076 & 0.1969 \\
\hline 14 & 0.0044 & 0.1728 \\
\hline 15 & 0.0036 & 0.1523 \\
\hline
\end{tabular}

\section{CONCLUSION}

From Table 1, one may observe that when we consider the crisp failure rate, we get single value of reliability at every instant of time. As the time increases, the value of reliability decreases and that can be seen from Figure 5 and we may also observe that there is a sharp down fall in the reliability due to the dichotomous state of failure rate estimation. But, from Table 2, one may observe that when the concept of posfust measure and necfust measure is applied for the failure rate estimation in the multi-state system, then be obtained in the form of closed interval including the lower and upper range.

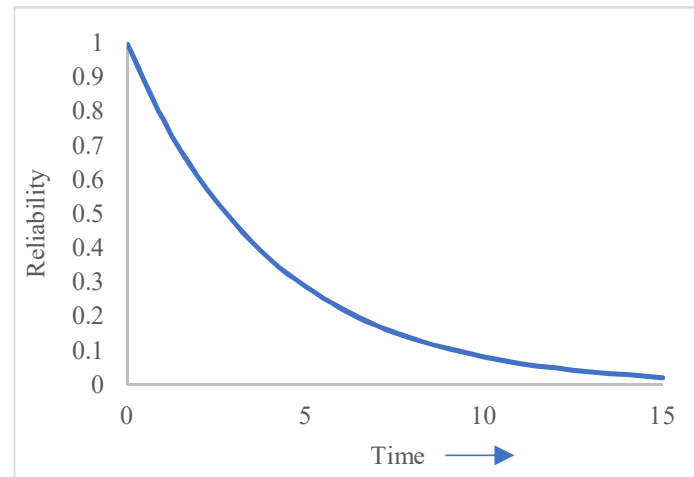

Figure 5. Presentation of conventional reliability

When the interval valued fuzzy failure rate (Posfust failure rate) is applied to this system, we get the values of the posfust reliability into lower and upper range. It can be also observed that classical reliability is a particular case of our study. Thus, fuzzy failure rate gives more realistic result in reliability estimation.

From Figure 6, it can be observed that present approach has efficient result than the probability approach. Thus, we can conclude that reliability estimation for the complex multistate systems using possibilistic approach is better alternative than the probabilistic approach due to the its capability to control the current uncertainty present in the system at any level.

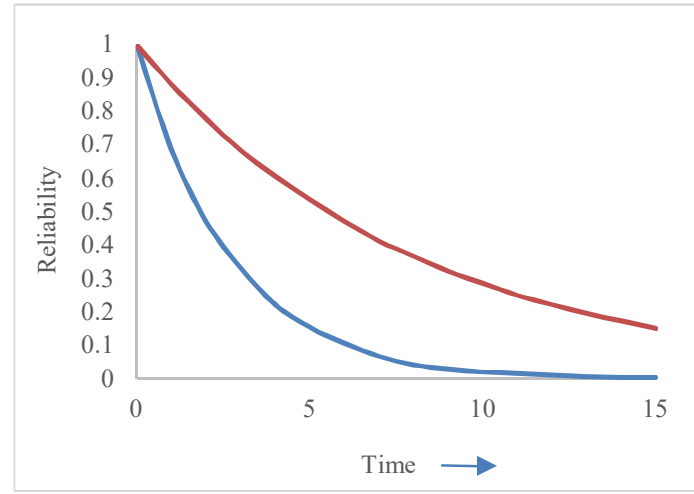

Figure 6. Posfust reliability obtained for a threestate system

\section{ACKNOWLEDGEMENT}

First author is thankful to CSIR for providing the financial assistance for the research work. 


\section{REFERENCES}

Bamrungsetthapong, W. and Pongpullponsak, A., Hybrid Fuzzy Estimation of System Reliability for MultiState System, Applied Mechanics and Materials, 2017. 866:387-391.

Bamrungsetthapong, W. and Pongpullponsak, A., System Reliability for non-repairable multi-state seriesparallel system using Fuzzy Bayesian inference based on prior interval Probabilities, International Journal General Systems, 2015, 44: 442-456.

Cai, K.Y. and Wen, C.Y., Fuzzy variables as a basis for a Theory of fuzzy reliability in the possibility context, Fuzzy sets and systems, 1991, 42:145-1.8.

Chen, T., Mesiar, Radko, Jun Lia and Andrea, Possibility and Necessity measures and integral equivalence, International Journal of Approximate Reasoning,2017, 86:62-72.

Dubois,D., and Prade, H., Fuzzy sets in approximate Reasoning, Part 1: inference with possibility distributions, Fuzzy Sets and Systems, 1991, 40:143202.

Inuiguchi M., and Kume,Y.,Fuzzy reasoning based on Uncertainty Generation rules using necessity measures, Jpn. J. Fuzzy Theory Systems, 1992, 4 (3) 329-344.

Inuiguchi, M., Greco, Salvatore, lowinski Roman $\mathrm{S}$ and Tanino, T., Possibility and necessity measure specification using modifiers for decision making under fuzziness, Fuzzy Sets and Systems, 2003, 137 :151-175.

Lisnianski, A. and Levitin, G., Multi-State System Reliability: Assessment Optimization Application, World Scientific Publishing, Singapore, 2003.

Liu, L. and Huang, H.Z., Reliability assessment for Fuzzy Multi-state systems, International Journal of Systems Science, 2010, 41:365-379.

Pandey, D. and Tyagi, S. K., Profust reliability of a Gracefully Degradable system, Fuzzy Sets and Systems, 2007, 158:794-803.

Zadeh, L.A., Fuzzy sets as a basis for a theory of Possibility, Fuzzy Sets and Systems, 1978, 1: 3- 28.

Zadeh, L.A., Fuzzy sets, Information and Control, 1965, $8: 338-56$.

\section{AUTHORS PROFILE}

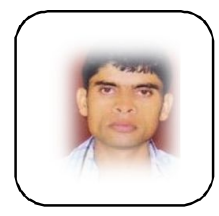

Harendra Yadav received his M. Sc degree in Mathematics from SSV PG College Hapur, India. He received CSIR-JRF in mathematical science. He is SRF (CSIR). He is pursuing his research work in Mathematics from Chaudhary Charan Singh University, Meerut. His research interest is in Fuzzy Reliability Theory.

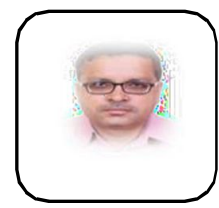

M. K. Sharma received his Ph.D. Degree in Fuzzy Reliability Theory from Chaudhary Charan Singh University, Meerut, India in 2007. He is currently working as an Associate Professor in the Department of Mathematics, Chaudhary Charan Singh University, Meerut, India. He has contributed more than 75 research articles to professional Journals. He has participated and presented more than 48 research articles in National and International conferences. His research interest includes Reliability theory,
Fuzzy logic, Intuitionistic fuzzy logic, vague logic and their applications in Engineering and Healthcare.

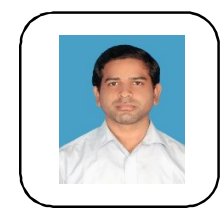

Dr. Vishnu Narayan Mishra is working as Associate Professor and Head of Department of Mathematics at Indira Gandhi National Tribal University, Lalpur, Amarkantak, Madhya Pradesh, India. He received the Ph.D. degree in Mathematics from Indian Institute of Technology, Roorkee in 2007. His research interests are in the areas of pure and applied mathematics including Approximation Theory, Summability Theory, Variational inequality, Fixed Point Theory, Operator Theory, Fourier Approximation, Non-linear analysis, Special functions, q-series and q-polynomials, signal analysis and Image processing, Optimization etc. He has published research articles in reputed international journals of mathematical and engineering sciences. He is referee and editor of several international journals in frame of pure and applied Mathematics \& applied economics. Dr. Mishra has more than 220 research papers to his credit published in several journals of repute as well as guided many postgraduate and $\mathrm{PhD}$ students (08Ph.D.). He has delivered talks at several international conferences, Workshops, Refresher programmes and STTPs etc. as Resource person. He is actively involved in teaching undergraduate and postgraduate students as well as $\mathrm{PhD}$ students. He is a member of many professional societies such as Indian Mathematical Society (IMS), International Academy of Physical Sciences (IAPS), Gujarat Mathematical Society, International Society for Research and Development (ISRD), Indian Academicians and Researchers Association (IARA), Society for Special Functions and their Applications (SSFA), Bharat Ganit Parishad etc. Citations of his research contributions can be found in many books and monographs, $\mathrm{PhD}$ thesis, and scientific journal articles, much too numerous to be recorded here. Dr. Mishra awarded as Prof. H.P. Dikshit memorial award at Hisar, Haryana on Dec. 31, 2019. Moreover, he serves voluntary as reviewer for Mathematica Reviews (USA) and Zentralblatt Math (Germany). 